\title{
A Study on Performance and Reusability of Certified and Uncertified Face Masks
}

Aerosol and Air Quality Research

\author{
Haebum Lee ${ }^{1}$, Seojeong Kim ${ }^{1}$, HungSoo Joo ${ }^{2}$, Hee-joo Cho ${ }^{1}$, Kihong Park ${ }^{1 *}$ \\ ${ }^{1}$ National Leading Research Laboratory (Aerosol Technology and Monitoring Laboratory), \\ School of Earth Science and Environmental Engineering, Gwangju Institute of Science and \\ Techonology (GIST), Gwangju, Korea \\ ${ }^{2}$ Department of Environmental Engineering, Anyang University, Gyeonggi-do, Korea
}

\section{ABSTRACT}

In this study, the performance (particle removal efficiency and breathing resistance) of several commercially available face masks (KF80-certified electrostatic and nanofiber filter masks, and an uncertified mask) was evaluated, along with their filter structure and composition. Also, the effects of the relative humidity $(\mathrm{RH})$ of incoming air, of water and alcohol exposure, and of reuse, on the performance of face masks were examined. Monodisperse and polydisperse sodium chloride particles were used as test aerosols. Except for the uncertified mask filter, $\mathrm{PM}_{2.5}$ removal efficiency was $>90 \%$. The nanofiber filter mask had the highest quality factor due to its low pressure drop and high removal efficiency, and densely packed nanofiber pore structure, and significant amounts of fluorine, carbon and oxygen. The removal efficiency of the KF80-certified mask was barely affected by the higher RH of incoming air. When the mask filters were soaked in water, their removal efficiency decreased. The uncertified mask filter showed the largest decrease in removal efficiency (26\%). When the mask was soaked in alcohol, the removal efficiency decreased to a greater degree than when soaked in water. The nanofiber mask filter showed the strongest resistance to alcohol among the tested mask filters. During evaluation of mask reusability, the removal efficiency of certified mask filters decreased by $4 \%$ over 5 consecutive days ( 2 hours per day), and that for the uncertified mask filter decreased significantly, by $30 \%$ after 5 days.

Keywords: Face mask, Aerosols, Removal efficiency, Breathing resistance

\section{INTRODUCTION}

Face masks play an important role in preventing particulate matter (PM) from entering the human respiratory system during breathing, particularly $\mathrm{PM}<10 \mu \mathrm{m}\left(\mathrm{PM}_{10}\right)$ or $2.5 \mu \mathrm{m}\left(\mathrm{PM}_{2.5}\right)$ in size (Langrish et al., 2009). The US Environmental Protection Agency recommends the use of masks for workers with high potential for exposure to high levels of fine particulates in indoor and outdoor environments (Rengasamy et al., 2004; Yang et al., 2015; Adhikari et al., 2018; Cherrie et al., 2018). In Korea, the Ministry of Environment also recommends that a certified mask be used in outdoor environments during periods of $\mathrm{PM}_{2.5}$ pollution (Yang et al., 2015; Jo et al., 2018). However, limited information is available on the reusability of face masks, or on the effects of relative humidity $(\mathrm{RH})$ and moisture on the performance of certified and uncertified masks.

Mask performance can be evaluated by measuring particle removal efficiency (or filtration efficiency) and breathing resistance (Newnum et al., 2010; Ramirez et al., 2015). Particle removal efficiency is mainly dependent on particle size and velocity, and the removal mechanism is related to impaction, diffusion, settling, and electrostatic attraction (Ramirez et al., 2015; Yang et al., 2015). Breathing resistance is associated with a pressure drop as the air passes through the mask, and can be affected by air velocity, particle loading, particle type (hygroscopic or non-hygroscopic), and RH (Miguel et al., 2003; Newnum et al., 2010; Mostofi et al., 2011; Ramires et al., 2015). Mask 
users typically stop wearing a mask when the breathing resistance increases and/or the surface of the mask becomes dirty. Leak tests can also be performed to evaluate masks.

Particle removal efficiency, breathing resistance, and the leak rate are measured to evaluate and grade masks (KF80, KF94, or KF99) in Korea (MFDS, 2017; Cho et al., 2019). The KF80 mask must have a particle removal efficiency $>80 \%$ at a flow rate of $95 \mathrm{~L} \mathrm{~min}^{-1}$, breathing resistance $<6.2 \mathrm{~mm} \mathrm{H}_{2} \mathrm{O}$ at a flow rate of $30 \mathrm{~L} \mathrm{~min}^{-1}$, and leak rate $<25 \%$. The $\mathrm{KF94}$ mask must have a particle removal efficiency $>94 \%$ at a flow rate of $95 \mathrm{~L} \mathrm{~min}^{-1}$, breathing resistance $<7.2 \mathrm{~mm} \mathrm{H}_{2} \mathrm{O}$ at a flow rate of $30 \mathrm{~L} \mathrm{~min}^{-1}$, and leak rate $<11 \%$. The KF99 mask must have particle removal efficiency $>99 \%$ at a flow rate of $95 \mathrm{~L} \mathrm{~min}^{-1}$, breathing resistance $<10.3 \mathrm{~mm} \mathrm{H} \mathrm{H}_{2} \mathrm{O}$ at a flow rate of $30 \mathrm{~L} \mathrm{~min}^{-1}$, and leak rate $<5 \%$ (MFDS, 2017). Sodium chloride ( $\mathrm{NaCl}$ ) particles are used as test aerosols for the KF80 mask, and both $\mathrm{NaCl}$ and paraffin oil particles are used for KF94 and KF99 masks. The mass concentrations of the $\mathrm{NaCl}$ and paraffin oil particles used for these tests are $8 \pm$ 4 and $20 \pm 5 \mathrm{mg} \mathrm{m}^{-3}$, respectively. The mask is tested after conditioning at $38 \pm 2.5^{\circ} \mathrm{C}$ and $85 \pm$ $5 \%$ RH over $24 \pm 1$ hours. Similarly, the mask grade in the US is determined by measuring particle removal efficiency (95\%, 99\%, or 100\%) for the most penetrating particle size (MPPS) and resistance level for oil (N: not resistant to oil, R: somewhat resistant to oil, P: strongly resistance to oil); masks may be graded based on both values (e.g., N95) (Bollinger and Schutz 1987; NIOSH, 2019). The mask grade can be obtained at a breathing resistance $<25 \mathrm{~mm} \mathrm{H}_{2} \mathrm{O}$ (inhalation) or $<35 \mathrm{~mm}$ (exhalation) at a flow rate of $85 \mathrm{~L} \mathrm{~min}^{-1}$ (Janssen et al., 2018).

Despite the grades, limited information is provided on the usable period or reusability of masks. Mask performance is expected to deteriorate as the wearing time increases. However, the level of deterioration depends on the wearing conditions, including the particle concentration, types of particles filtered, existence of condensable vapors, $\mathrm{RH}$, and so on. The performance of electrostatic filter masks, i.e., particle removal efficiency, can reportedly be affected by the presence of moisture and RH (Motyl and Łowkis, 2006). However, others have reported that the effect of RH on particle removal efficiency is insignificant (Yang and Lee, 2005). Breathing resistance can also be affected by RH (Roberge et al., 2010).

In this study, we evaluated the performance of various commercially available masks by measuring particle removal efficiency, breathing resistance, and leak rate. The effects of the RH of incoming air, and water and alcohol exposure on mask performance, and its reusability was also examined. Electrostatic filter masks (certified), nanofiber filter masks (certified), and uncertified masks were tested. The surface characteristics and composition of the mask filters were analyzed using a scanning electron microscope/energy dispersive X-ray analyzer (SEM/EDX) (S-4700, Hitachi, Japan). Monodisperse $\mathrm{NaCl}$ particles $(50,100,200$, and $300 \mathrm{~nm}$ ) and polydisperse $\mathrm{NaCl}$ particles were used to measure particle removal efficiency. The $\mathrm{RH}$ of incoming air was controlled to examine the effects of RH on mask filter performance. Additionally, the mask filter was soaked in water and alcohol, dried, and then tested for deterioration of the mask filter under exposure to moisture and organic materials. To evaluate mask reusability, particle removal efficiency and breathing resistance were continuously measured after using the masks for 2 hours per day for 1-5 days.

\section{METHODS}

\subsection{Target Masks}

Commercially available KF80 grade and uncertified masks were tested, as summarized in Table 1. Samples A, B, C, and E are electrostatic filter masks, and sample D is a nanofiber filter mask. All mask filters were cut into 47-mm-diameter circles, and the mask filter weights $\left(\mathrm{g} \mathrm{m}^{-2}\right.$ )

Table 1. Summary of the commercial face masks tested in this study.

\begin{tabular}{llllll}
\hline & Sample A & Sample B & Sample C & Sample D & Sample E \\
\hline Certification grade & KF80 & KF80 & KF80 & KF80 & Uncertified \\
Number of layers & 4 & 4 & 4 & 3 & 3 \\
Filter type & Electret filter & Electret filter & Electret filter & Nanofiber filter & Electret filter \\
Mask filter weight $\left(\mathrm{g} \mathrm{m}^{-2}\right)$ & 253.6 & 184.4 & 144.1 & 98.0 & 69.2 \\
Price (won) & 1,900 & 1,200 & 1,800 & 2,000 & 171 \\
\hline
\end{tabular}


were then measured using an electronic scale (Cubis, Sartorius, Germany). Among those tested, the E mask filter was the lightest. We also counted the number of layers in each mask.

\subsection{Assessment of Mask Filter Structure and Composition}

The structure, surface characteristics, and elemental composition of the mask filters, which consisted of several layers, were determined using SEM/EDX. Mask filters A-C consisted of four layers, with the third layer being that mainly responsible for removing particles. The $D$ and $E$ mask filters had three layers, and the second layer was the filter layer.

\subsection{Evaluation of Mask Filter Performance}

Fig. 1 shows a schematic of the experimental setup for evaluating mask performance. Tests of particle removal efficiency, breathing resistance, and leak rate were performed. The experimental setup comprises aerosol generation, $\mathrm{RH}$ control, and measurement systems. The polydisperse aerosols were generated from $1 \mathrm{wt} \% \mathrm{NaCl}$ solution using an atomizer (3076, TSI, USA) and dried by passage through a diffusion dryer before being introduced into the mask filter. The polydisperse aerosols were used to determine particle removal efficiency based on the measured mass concentration (i.e., the $\mathrm{PM}_{2.5}$ mass concentration). The mask filter was cut to form a 47-mm-diameter circle and mounted on a filter holder.

A differential mobility analyzer (DMA) (3081, TSI, USA), which can select particles of a predefined size, was used to generate monodisperse aerosols. Size is classified according to the DMA as electrical mobility equivalent (Wang et al., 1990; Kelly et al., 1992). The aerosol flow from the DMA was mixed with clean air to achieve the desired flow rates before the air was introduced into the mask filter. The particle number concentration and mass concentration before and after the air passed through the mask filter were measured with a concentration particle counter (CPC) (3772, TSI, USA) and dust monitor (DustTrak, TSI, USA), respectively. The particle removal efficiency of size-resolved particles $(50,100,200$, and $300 \mathrm{~nm}$ ) was determined from the particle number

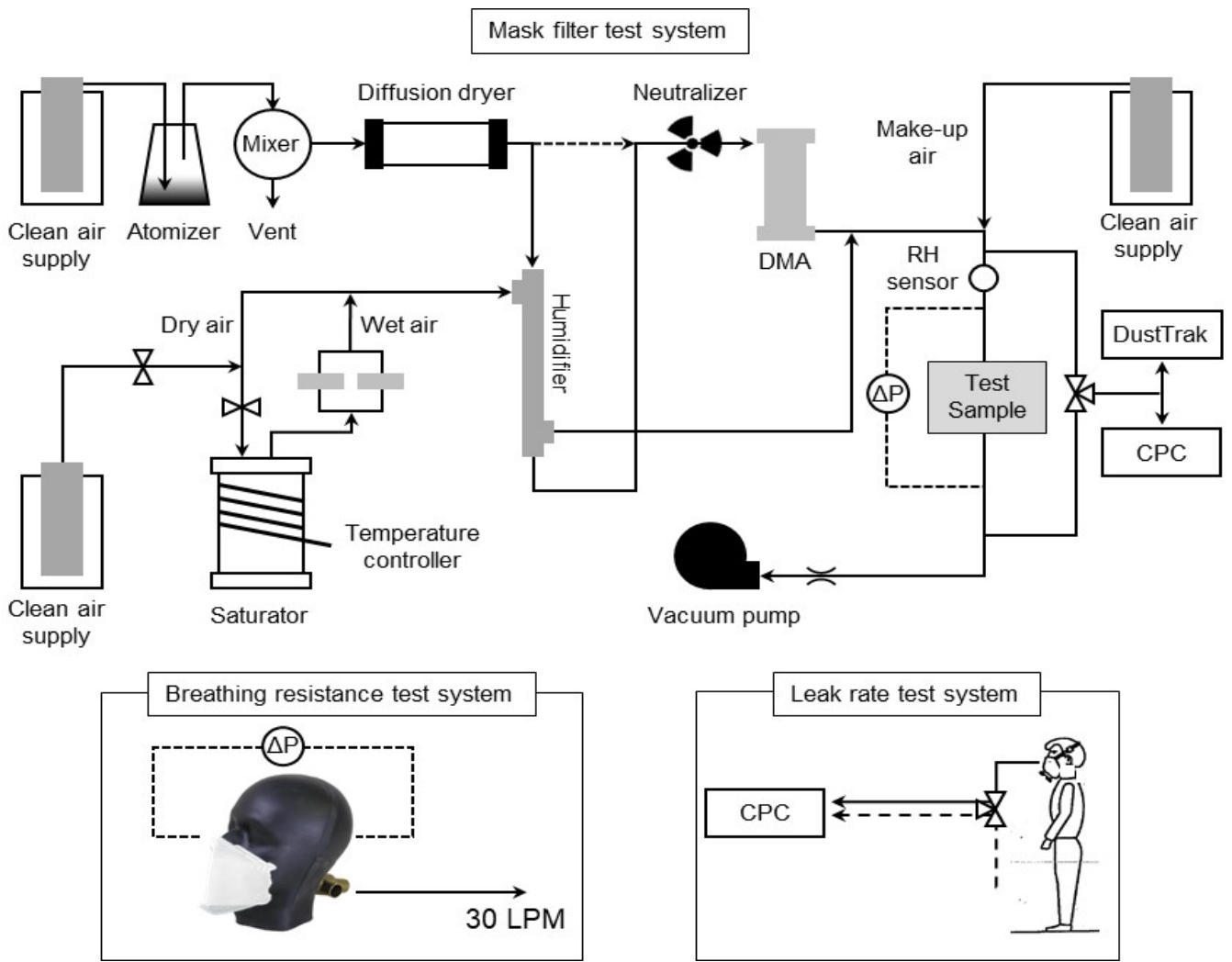

Fig. 1. Schematic of the experimental setup to measure the particle removal efficiency of sizeresolved $\mathrm{NaCl}$ particles $(50,100,200$, and $300 \mathrm{~nm}$ ) and polydisperse $\mathrm{NaCl}$ particles under various $\mathrm{RH}$ conditions. Pressure drop, breathing resistance, and leak rate were measured. 
concentration. The particle removal efficiency of polydisperse particles was determined based on the $\mathrm{PM}_{2.5}$ mass concentration (i.e., $\mathrm{PM}_{2.5}$ removal efficiency). The measured $\mathrm{PM}_{2.5}$ mass concentration in the aerosol flow ranged from $4.3-6.1 \mathrm{mg} \mathrm{m}^{-3}$.

The pressure drop before and after applying the mask filter was measured using a differential pressure gauge (DPM, Sensys, Korea). The flow rate through the mask filter was $20 \mathrm{~L} \mathrm{~min}^{-1}$. The effective diameter of the mask filter mounted on the filter holder was $34 \mathrm{~mm}$, the area of the mask filter was approximately $9.1 \mathrm{~cm}^{2}$, and the filtration speed was $37 \mathrm{~cm} \mathrm{~s}^{-1}$.

A quality factor $\left(q_{f}\right)$ was determined for the mask filter (Cho et al., 2011; Huang et al., 2013) using the following equation:

$q_{f}=\frac{\ln \left(\frac{1}{P_{\text {penetration }}}\right)}{\Delta P_{\text {pressure }}}$

where $P_{\text {penetration }}$ is particle penetration (= 1 - particle removal efficiency), and $\Delta P_{\text {pressure }}$ is the pressure drop through the filter. A high-quality filter should have high particle removal efficiency and a low pressure drop, yielding a high $\mathrm{q}_{\mathrm{f}}$. Hence, the $\mathrm{q}_{\mathrm{f}}$ can be a good measure of filter performance.

To determine particle removal efficiency under humid conditions, wet air was produced from a saturation chamber, as shown in Fig. 1. The wet air was mixed with dry air to create air with the desired RH. The humid air flow was mixed with aerosol flow in the Nafion tube (MH-110-24S-4, Perma Pure, USA), where the water vapor molecule exchange took place. The RH of the aerosol flow was measured at the inlet of the mask filter holder (Fig. 1). The measurement uncertainty for $\mathrm{RH}$ was about $2 \%$. The experiment was conducted at $\mathrm{RH}<10 \%$ (dry), $40 \%$, and $70 \%$ (humid) conditions. The maximum $\mathrm{RH}$ was set to $70 \%$ because $\mathrm{NaCl}$ particles can grow by absorbing water at $\mathrm{RH}>75 \%$. Particle concentrations before and after the mask filter was applied were measured three times for 30 seconds each time, and the average value was used to determine particle removal efficiency.

\subsection{Measurement of Breathing Resistance and Leak Rate}

The mask was placed on a face model, as shown in Fig. 1, and breathing resistance was determined by measuring the pressure drop through the face model at a flow rate of $30 \mathrm{~L} \mathrm{~min}^{-1}$. The leak rate test was performed with both men and women wearing the mask. The measurement tube was inserted inside the mask at the location of the mouth. The leak rate was determined by measuring the particle concentrations in room air and inside the mask for 30 seconds. The particle concentration inside the mask (lower $30 \%$ ) was divided by that in room air to calculate the leak rate.

\subsection{Evaluation of Mask Reusability}

Three types of experiments were conducted to evaluate mask reusability. First, particle removal efficiency was measured after exposing the mask filter to humid air at $\mathrm{RH} 90 \pm 9 \%$ for 2-6 hours. Second, particle removal efficiency was measured after soaking the mask filter in deionized (DI) water or isopropyl alcohol (IPA) for 3 hours and drying it at $70^{\circ} \mathrm{C}$ for 12 hours. The IPA was used to evaluate the effects of organic materials on filter performance. Electrical attraction in the electret filter could be reduced under water and alcohol exposure. Third, the reusability of masks $B$ and $E$ was tested during wearing in real-life conditions. The mask was used for 5 consecutive days ( 2 hours per day). After use, it was sprayed with water and dried for 12 hours, and then reused by the same person on the next day. The particle removal efficiency and breathing resistance were measured in a manner similar to that described earlier.

\section{RESULTS AND DISCUSSION}

\subsection{Mask Filter Structure and Elemental Composition}

Table 2 shows the structure and elemental composition of the mask filters (A-E) measured using SEM/EDS. The $D$ and $E$ mask filters had three layers, whereas the $A-C$ mask filters had four. The shapes of the first (outer) layer and last (inner) layer were similar among the $B, D$, and $E$ mask 


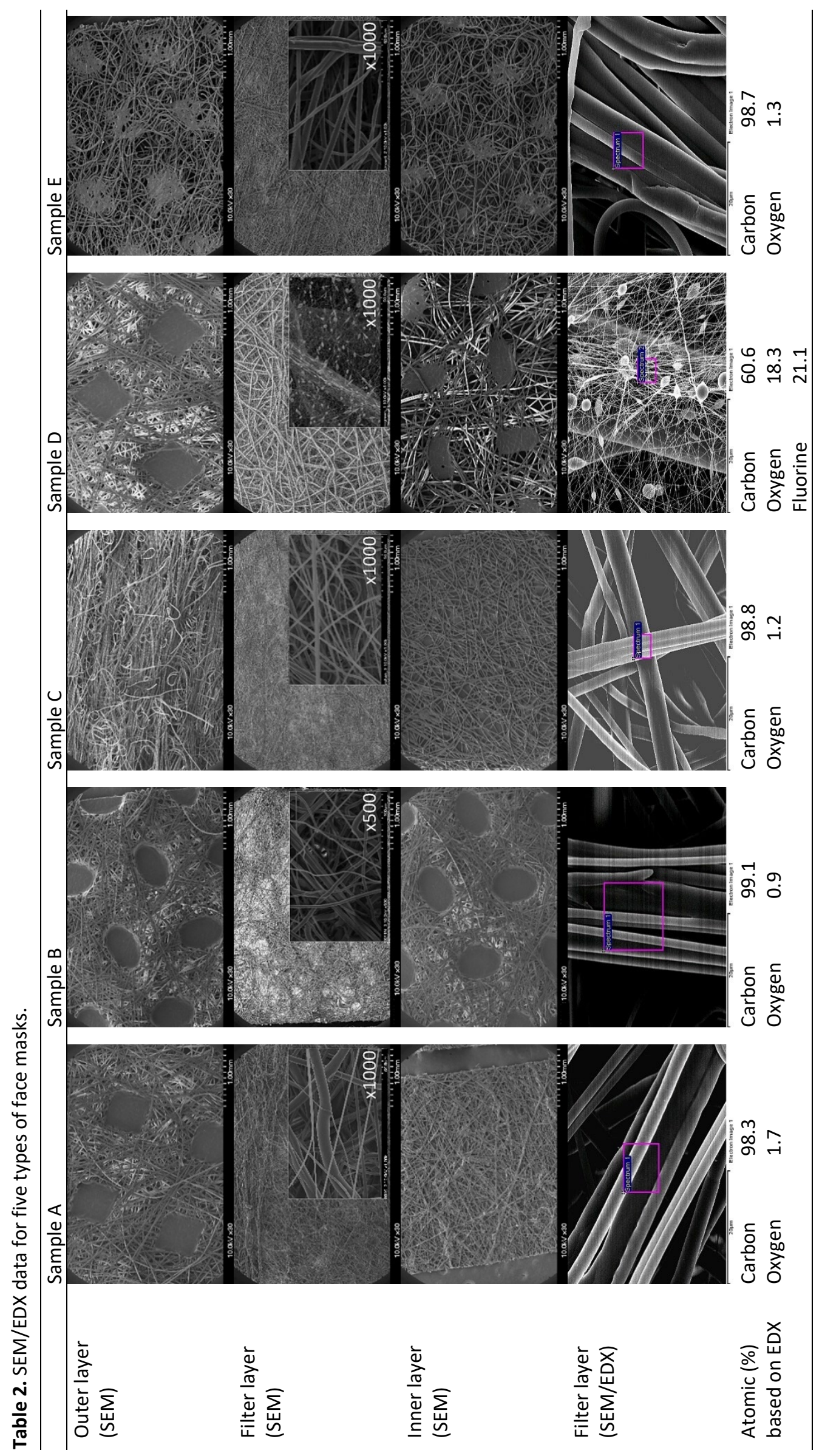


filters, as shown in Table 2. The first and last layers were constructed from nonwoven filter materials. The middle layer (i.e., filter layer) was made from very fine, dense fibers. Most of the incoming particles were removed by the filter layer. A filter layer consisting of thin and dense nanofibers was observed in the $D$ mask filter. The nanofiber filter had a more densely packed pore structure compared to the other types of filters, leading to high potential for physical contact with incoming particles.

As shown in Table 2, the mask filters consist primarily of carbon and oxygen elements. This is because the filters were typically made of polymers with low electrical conductivity, such as polypropylene, polycarbonate, polyurethane, and polyethylene oxide (Motyl and Łowkis, 2006). The D mask filter also contained a significant amount of fluorine. This suggests that the method and materials for making nanofiber filters should be different from those used for electret filters. The nanofibers containing fluorine should comprise a mixture of polyvinylidene fluoride (PVDF) and polytetrafluoroethylene (PTFE), and the pore size of nanofiber filters can be controlled by adjusting the amount of PTFE (Lolla et al., 2016; Wang et al., 2016). The nanofiber filter has often been reported to have higher filtration efficiency, lower pressure drop, and higher specific surface area and charge stability than other types of filters (Lolla et al., 2016; Wang et al., 2016).

\subsection{Mask Filter Performance}

Fig. 2(a) shows the removal efficiency of size-resolved particles $(50,100,200$, and $300 \mathrm{~nm})$ for mask filters. The particle removal efficiency was determined from the particle number concentration under the dry condition $(<10 \% \mathrm{RH})$. The removal efficiency of $200-\mathrm{nm}$ particles was lowest among the tested particle sizes for the $A, B, C$, and $E$ mask filters, whereas it was the highest for 50-nm particles. Because the A, B, C, and E mask filters were electret, both electrostatic attraction and diffusion played important roles in removing nanoparticles by filtration. The MPPS was $200 \mathrm{~nm}$ for these electret filters. In contrast, the MPPS of the D mask filter was smaller than that of the electret filters, because the removal efficiency for small particles decreased, possibly due to the relatively low electrostatic attraction of the nanofiber filter.

Differences in flow rates, filter types, filter media sizes, and electrostatic forces might have led to the difference in MPPS ( $200 \mathrm{~nm}$ except for a nanofiber mask) and penetration compared to previous results (Eshbaugh et al., 2008; Rengasamy et al., 2009; Shaffer and Rengasmy, 2009; Rengasamy et al., 2013). The flow rate of $20 \mathrm{~L} \mathrm{~min}^{-1}$ used here was relatively low compared to previous studies that used a flow rate of $85 \mathrm{~L} \mathrm{~min}^{-1}$ (Rengasamy et al., 2009; Li et al., 2012); similarly, the current filter size was smaller, and the filtration velocity higher, than in previous studies. The calculated filtration velocity was $37 \mathrm{~cm} \mathrm{~s}^{-1}$. With higher filtration velocity, the particle

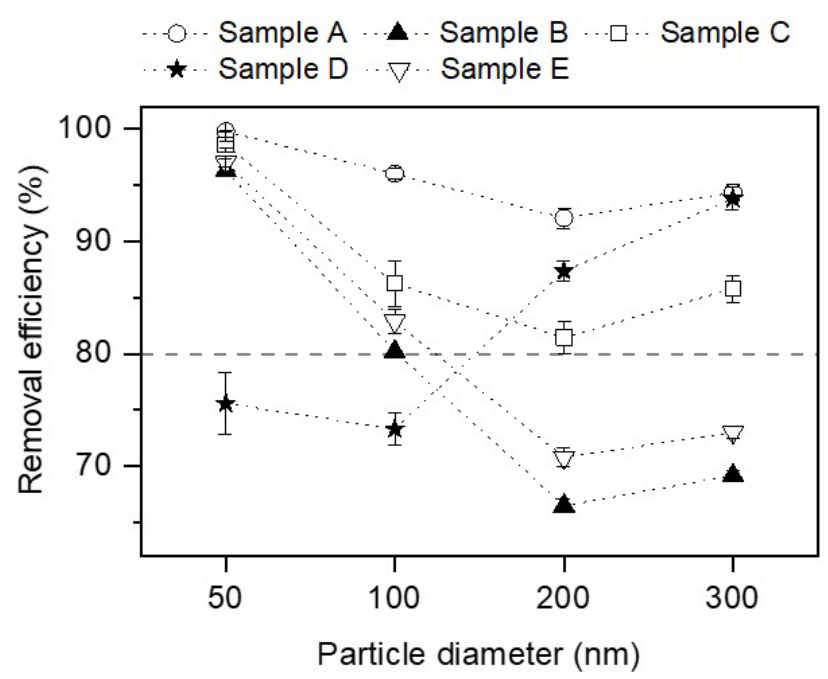

(a)

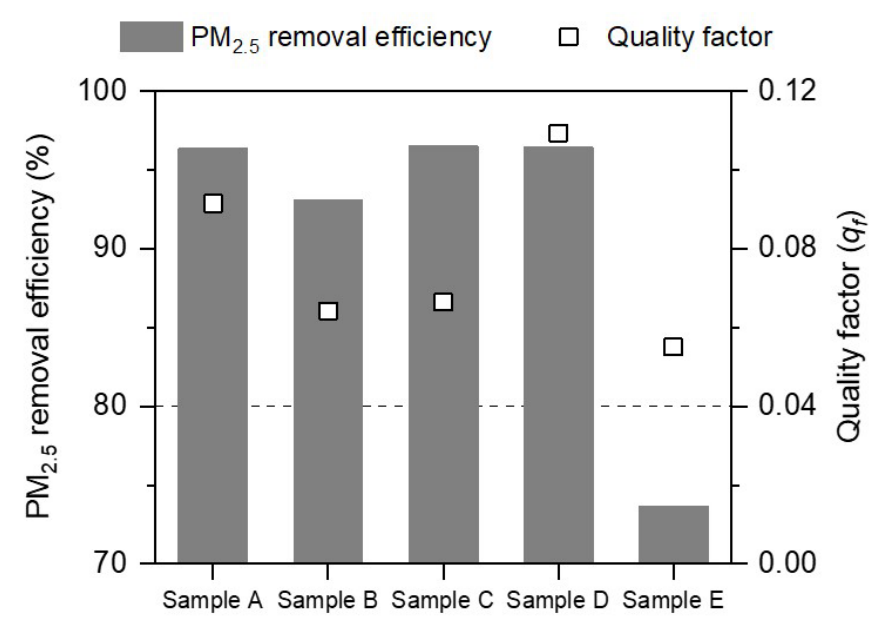

(b)

Fig. 2. (a) Particle removal efficiency of 50-, 100-, 200-, and 300-nm NaCl particles based on the particle number concentration; (b) $\mathrm{PM}_{2.5}$ removal efficiency and quality factor based on $\mathrm{PM}_{2.5}$ mass concentration for five types of face mask filters under the dry condition $(<10 \% \mathrm{RH})$. 
residence time is shortened, and the removal efficiency of small particles is reduced more dramatically than that of large particles, leading to smaller MPPS (Balazy et al., 2006; Alderman et al., 2008; Jung et al., 2013). The removal efficiency of the tested filters was relatively low compared to previous results obtained using high-grade electrostatic filters (Eshbaugh et al., 2008; Alderman et al., 2008). Although the E mask was uncertified, its removal efficiency of size-resolved particles ( 50 and $100 \mathrm{~nm}$ ) based on particle number concentration was comparable to those of other mask filters.

Fig. 2(b) shows the particle removal efficiency based on $\mathrm{PM}_{2.5}$ mass concentration for mask filters. The mask grade and certification procedure to determine the particle removal efficiency were based on the $\mathrm{PM}_{2.5}$ mass concentration. The $\mathrm{PM}_{2.5}$ removal efficiency of the $\mathrm{E}$ mask filter (uncertified mask) was the lowest (74\%); the other mask filters (KF80-certified masks) had removal efficiency values $>90 \%$, consistent with the certified grade. Measures of removal efficiency based on the particle number concentration of monodisperse particles and removal efficiency based on the mass concentration of polydisperse particles reportedly differed (Martin and Moyer, 2000; Rengasamy et al., 2009). In the determination of $\mathrm{PM}_{2.5}$ removal efficiency, all particles $>2.5$ um were included. Thus, the $\mathrm{PM}_{2.5}$ removal efficiency for the $\mathrm{E}$ mask filter may be lower than values based on the number concentrations of particles (50, 100, 200, and $300 \mathrm{~nm}$ ). As shown in Table 1, the filter weight of the E mask was lower compared to the other types of mask filters (i.e., those not having a dense filter structure), which also contributed to the lowest particle removal efficiency. The electrostatic and material properties of the filters were not investigated in details in this study. The $q_{f}$ values for the mask filters are shown in Fig. 2(b). The $D$ mask filter had the highest $\mathrm{q}_{\mathrm{f}}$ because, among the mask filters, it had relatively high particle removal efficiency and a low pressure drop.

Fig. 3(a) shows the breathing resistance of the masks. The flow rate in the breathing resistance test was $30 \mathrm{~L} \mathrm{~min}^{-1}$. All of the masks met the $\mathrm{KF} 80$ grade requirement $\left(<6.2 \mathrm{~mm} \mathrm{H}_{2} \mathrm{O}\right)$. The breathing resistance values of the $A$ and $B$ masks were somewhat higher than those of the $C, D$, and $E$ masks. As shown in Fig. 3(b), the A mask had the lowest leak rate $(1.6 \pm 0.5 \%)$, and the $E$ mask had the highest leak rate ( $44 \pm 13 \%)$. The $\mathrm{C}$ and $\mathrm{E}$ masks had higher standard deviations compared to the other masks. Differences in gender, face size and shape, and wearing patterns could affect the leak rate. The leak rate of masks worn by men was $<30 \%$, which was lower than that of the masks worn by women. The leak rate of the $\mathrm{E}$ mask filter (uncertified) worn by women was $>60 \%$.

Fig. 4 compares the particle removal efficiency among mask filters under humid $(40 \%$ and $70 \%$ $\mathrm{RH})$ and dry conditions $(<10 \% \mathrm{RH})$. The average removal efficiency was calculated for $50-, 100-$, 200-, and 300-nm particles. The particle removal efficiency of the $\mathrm{E}$ mask filter at $40 \% \mathrm{RH}$ decreased by approximately $5 \%$ compared to that at $70 \% \mathrm{RH}$. No significant changes in particle removal efficiency with $\mathrm{RH}$ conditions ( $40 \%$ and $70 \% \mathrm{RH}$ ) were found for any of the certified mask filters. Also, the pressure drop was not affected by the $\mathrm{RH}$ condition.

\subsection{Mask Reusability Evaluation}

Fig. 5(a) compares particle removal efficiency among the mask filters after exposure to humid $(90 \% \mathrm{RH})$ and dry conditions for 2 hours. No significant difference in particle removal efficiency before and after exposure to the humid condition was observed. The particle removal efficiency

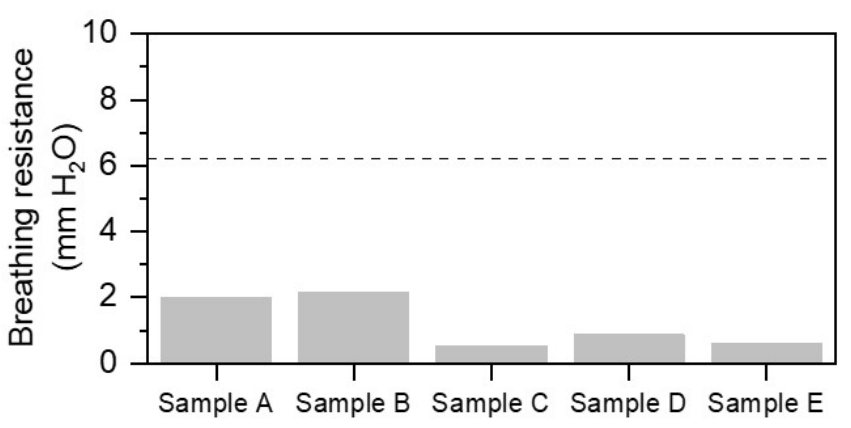

(a)

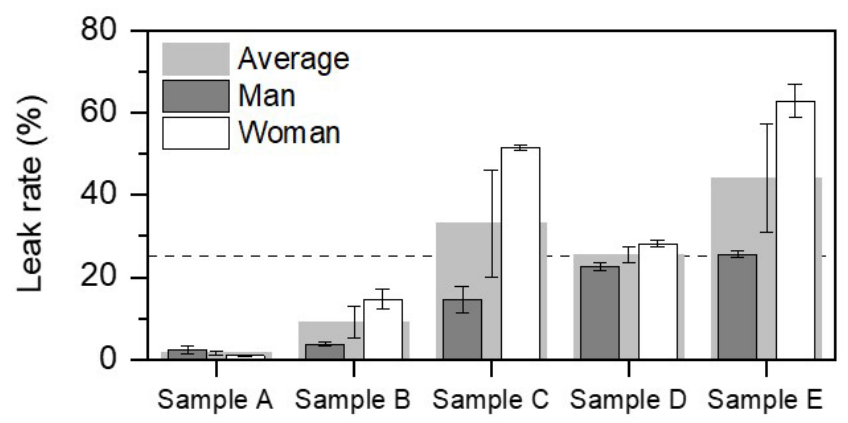

(b)

Fig. 3. (a) Breathing resistance $\left(\mathrm{mmH}_{2} \mathrm{O}\right)$ and (b) leak rate (\%) for five types of face masks under the dry condition $(<10 \% \mathrm{RH})$. 


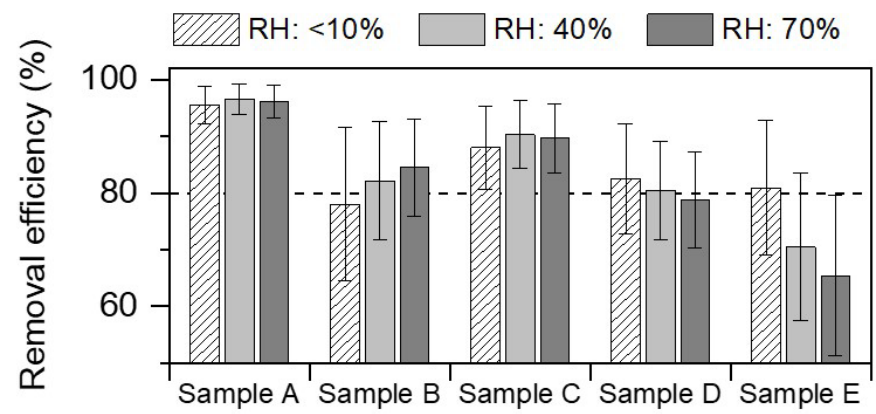

Fig. 4. Comparison of the particle removal efficiency (\%) with incoming air flow among five types of face mask filters under different $\mathrm{RH}$ conditions $(<10 \%, 40 \%$, and $70 \%)$. The average particle removal efficiency is based on 50-, 100-, 200-, and 300-nm particles.

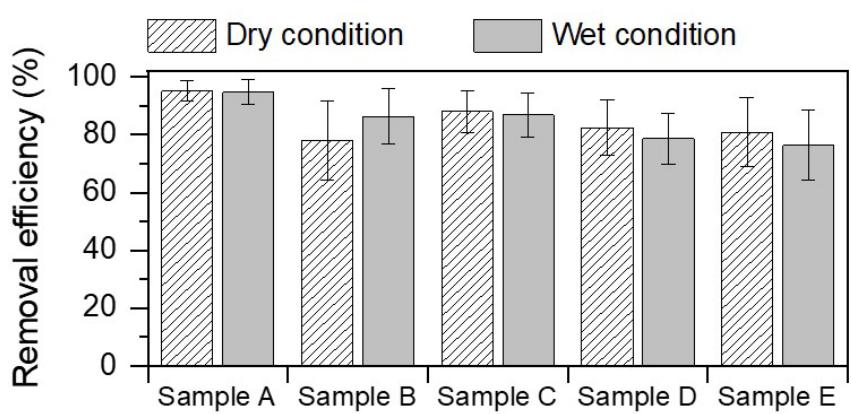

(a)

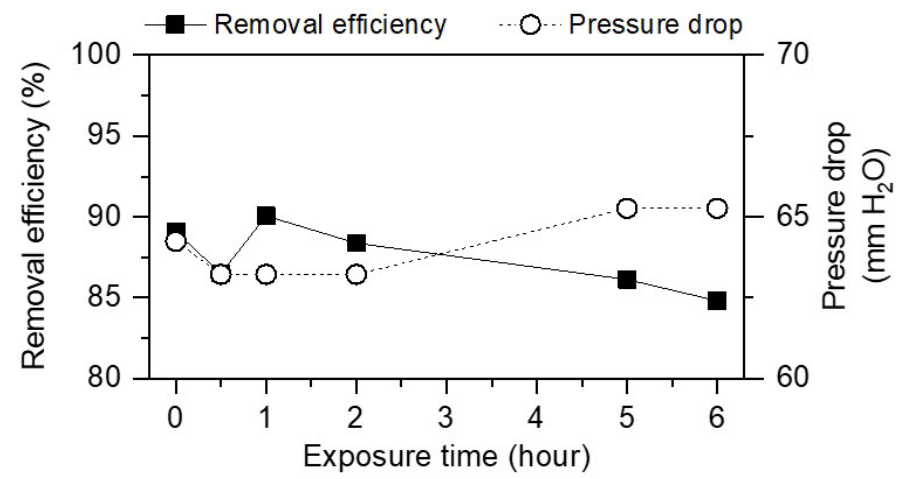

(b)

Fig. 5. (a) Comparison of the particle removal efficiency (\%) among five types of face mask filters exposed to dry (<10\% RH) and wet $(90 \% \mathrm{RH})$ conditions for 2 hours (particle removal efficiency is based on 50-, 100-, 200-, and 300-nm particles). (b) Particle removal efficiency (\%) and pressure drop $\left(\mathrm{mmH}_{2} \mathrm{O}\right)$ for type $\mathrm{C}$ face mask filters exposed to wet conditions $(90 \% \mathrm{RH})$ for up to 6 hours.

of the uncertified $\mathrm{E}$ mask filter decreased by $5 \%$ after exposure to the humid condition. Fig. 5 (b) shows the particle removal efficiency and pressure drop of the $\mathrm{C}$ mask filter after exposure to humid condition ( $90 \% \mathrm{RH}$ ) for up to 6 hours. The particle removal efficiency was reduced by up to $4 \%$ under the humid condition, with a decreasing rate of $0.6 \% \mathrm{~h}^{-1}$. Our data suggest that the effect of humidity on the particle removal efficiency of the mask filters tested here was small. In the case of electret filters, particle removal efficiency reportedly decreased under the humid condition because the surface charge decreased as humidity increased (Ikezaki et al., 1995; Łowkis and Motyl, 2001). It is possible that the filters tested here had surface treatments that provided strong water resistance (Yang and Lee, 2005).

The particle removal efficiency of mask filters soaked in water for 3 hours is shown in Fig. 6. Particle removal efficiency decreased for all mask filters, with the particle removal efficiency of the $E$ mask (uncertified) decreasing by $26 \%$. The particle removal efficiency of mask filters soaked in alcohol (IPA) for 3 hours decreased by $13-37 \%$, suggesting that the filters are not as resistant to alcohol as to water. The particle removal efficiency of the D mask filter decreased by $13 \%$, and that of the $E$ mask filter decreased by $37 \%$. These data suggest that the D mask filter (nanofiber filter) had higher resistance to organic materials than the electret filters.

Fig. 7 shows the particle removal efficiency and breathing resistance of the B and $E$ mask filters after 5 consecutive days of real-life use ( 2 hours per day). After each use, the mask was sprayed with water and dried over 12 hours before use on the next day. After 5 consecutive days, the particle removal efficiency of the B mask filter decreased by $4 \%$ compared to the new one, while the particle removal efficiency of the $E$ mask filter decreased by $18-30 \%$. The particle removal efficiency of the E mask filter significantly decreased relative to the B mask filter after 1 day of use. The E mask filter was less resistant to water than the other mask filters (see Fig. 6). Since the 


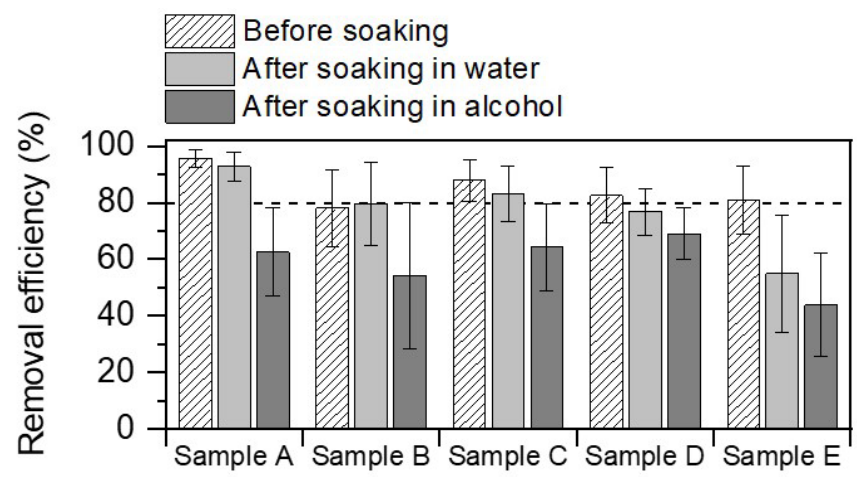

Fig. 6. Comparison of the particle removal efficiency (\%) among five types of face mask filters after soaking in water and alcohol. The average particle removal efficiency is based on 50-, 100-, 200-, and 300-nm particles.

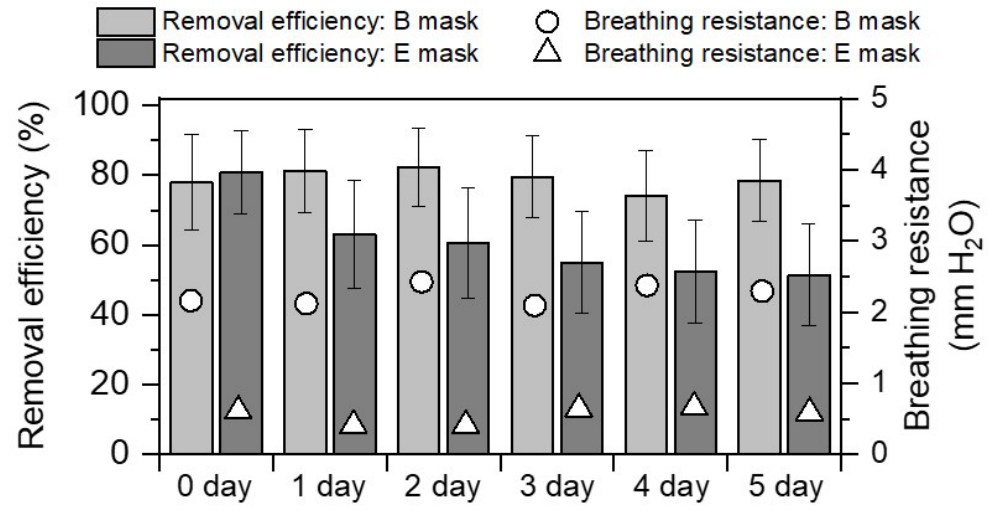

Fig. 7. Particle removal efficiency (\%) and breathing resistance $\left(\mathrm{mm} \mathrm{H}_{2} \mathrm{O}\right)$ for type $B$ and $E$ face mask filters after real-life use for 5 consecutive days ( 2 hours per day). The average particle removal efficiency is based on 50-, 100-, 200-, and 300-nm particles.

mask was sprayed with water and dried after use, a greater reduction of particle removal efficiency was seen for the $E$ than $B$ mask filters. However, little difference in breathing resistance after reuse was found between the two masks. Under the current experimental conditions, the increase in breathing resistance due to increased particle collection (i.e., aerosol loading effect) was not significant. The level of indoor and outdoor $\mathrm{PM}_{2.5}$ mass concentrations was approximately $25 \mu \mathrm{g} \mathrm{m}^{-3}$ on average, which was much lower than in highly polluted workplaces. More diverse exposure conditions, to simulate those in real life should be employed in future studies testing the reusability of masks.

\section{CONCLUSIONS}

The particle removal efficiency and breathing resistance of electret filter masks (KF80), nanofiber filter masks (KF80), and uncertified masks were evaluated using monodisperse and polydisperse $\mathrm{NaCl}$ particles. The $\mathrm{PM}_{2.5}$ removal efficiency of all masks except the uncertified mask was above $90 \%$. The mask with the nanofiber filter had the highest $q_{f}$, with high removal efficiency and a low pressure drop. The mask filter structure and elemental composition data showed that the nanofiber filter had nano-sized fibers with many pores, and contained significant amounts of fluorine, carbon and oxygen. The particle removal efficiency of KF80 mask filters under humid air conditions was not significantly different from that under dry air conditions. However, the particle removal efficiency of all mask filters decreased after they were soaked in water. The highest performance degradation was found for the uncertified mask. In addition, the particle removal efficiency for mask filters decreased by $13-37 \%$ after they were soaked in alcohol. The nanofiber 
filter had higher resistance to organic materials compared to the electret filter. Reusability tests suggested that the particle removal efficiency of the uncertified mask decreased more significantly, by $18-30 \%$, than that of certified masks after real-life use for 5 consecutive days ( 2 hours per day).

\section{ACKNOWLEDGMENTS}

This research was supported by a National Research Foundation of Korea (NRF) grant founded by the Korea government (MSIT) (NRF-2014M3C8A5030612 and NRF-2019R1A2C3007202).

\section{DISCLAIMER}

The authors declare that they have no conflict of interest.

\section{REFERENCES}

Adhikari, A., Mitra, A., Rashidi, A., Ekpo, I., Schwartz, J., Doehling, J. (2018). Field evaluation of N95 filtering facepiece respirators on construction jobsites for protection against airborne ultrafine particles. Int. J. Environ. Res. Public Health. 15, 1958. https://doi.org/10.3390/ijerph1 5091958

Alderman, S.L., Parsons, M.S., Hogancamp, K.U., Waggoner, C.A. (2008). Evaluation of the Effect of media velocity on filter efficiency and most penetrating particle size of nuclear grade highefficiency particulate air filters. J. Occup. Environ. Hyg. 5, 713-720. https://doi.org/10.1080/15 459620802383934

Balazy, A., Toivola, M., Reponen, T., Podgorski, A., Zimmer, A., Grinshpun, S.A. (2006). Manikinbased performance evaluation of N95 Filtering-facepiece respirators challenged with nanoparticles. Ann. Occup. Hyg. 50, 259-269. https://doi.org/10.1093/annhyg/mei058

Bollinger, N.J., Schutz, R.H. (1987). NIOSH Guide to industrial respiratory protection. National Institute for Occupational Safety and Health (NIOSH).

Cherrie, J.W., Apsley, A., Cowie, H., Steinle, S., Mueller, W., Lin, C., Horwell, C.J., Sleeuwenhoek, A., Loh, M. (2018). Effectiveness of face masks used to protect Beijing residents against particulate air pollution. Occup. Environ. Med. 75, 446-452. https://doi.org/10.1136/oemed2017-104765

Cho, H.W., Yoon, C.S., Lee, J.H., Lee, S.J., Viner, A., Johnson, E.W. (2011). Comparison of pressure drop and filtration efficiency of particulate respirators using welding fumes and sodium chloride. Ann. Occup. Hyg. 55, 666-680. https://doi.org/10.1093/annhyg/mer032

Cho, J., Shin, C. (2019). A study on indoor sources-outdoor penetration pathways and performance options on products to counter against fine dust particles. Korean J. Air-Cond. Refrig. Eng. 31, 332-341. https://doi.org/10.6110/KJACR.2019.31.7.332

Eshbaugh, J.P., Gardner, P.D., Richardson, A.W., Hofacre, K.C. (2008). N95 and P100 respirator filter efficiency under high constant and cyclic flow. J. Occup. Environ. Hyg. 6, 52-61. https://doi.org/10.1080/15459620802558196

Huang, S.H., Chen, C.W., Kuo, Y.M., Lai, C.Y., McKay, R., Chen, C.C. (2013). Factors affecting filter penetration and quality factor of particulate respirators. Aerosol Air Qual. Res. 13, 162-171. https://doi.org/10.4209/aaqr.2012.07.0179

Ikezaki, K., Iritani, K., Nakamura, T., Hori, T. (1995). Charge stability of TPX film electrets. J. Electrost. 35, 41-46. https://doi.org/10.1016/0304-3886(95)00017-5

Janssen, L., Johnson, A.T., Johnson, J.S., Mansdorf, S., Meici, O.R., Metzler, R.W., Rehak, T.R., Szalajda, J.V., Moore, J. (2018). Chemical, biological, radiological, and nuclear (CBRN) respiratory protection handbook. Pittsburgh, PA: U.S. Department of Health and Human Services, Centers for Disease Control and Prevention, National Institute for Occupational Safety and Health, DHHS (NIOSH) Publication No. 2018-166. https://doi.org/10.26616/NIOSHPUB2018166

Jo, H.J., Park, S.W., Lee, H.I., Lee, S.W. (2018). Health effects caused by particulate matter and guidelines for health care. Public Health Weekly Report. 11, 458-462.

Jung, C.H., Park, H.S., Kim, Y.P. (2013). Theoretical study for the most penetrating particle size of 
dust-loaded fiber filters. Sep. Purif. Technol. 166, 248-252. https://doi.org/10.1016/j.seppur.2 013.05.045

Kelly, W., McMurry, P.H. (1992). Measurement of particle density by inertial classification of differential mobility analyzer-generated monodisperse aerosols. Aerosol Sci. Technol. 17, 199212. https://doi.org/10.1080/02786829208959571

Langrish, J.P., Mills, N.L., Chan, J.K., Leseman, D.L., Aitken, R.J., Fokkens, P.H., Cassee, F.R., Li, J., Donaldson, K., Newby, D.E., Jiang, L. (2009). Beneficial cardiovascular effects of reducing exposure to particulate air pollution with a simple facemask. Part. Fibre Toxicol. 6, 8. https://doi.org/10. 1186/1743-8977-6-8

Li, L., Zuo, Z., Japuntich, D.A., Pui, D.Y.H. (2012). Evaluation of filter media for particle number, surface area and mass penetrations. Ann. Occup. Hyg. 56, 581-594. https://doi.org/10.1093/ anhyg/mes034

Lolla, D., Lolla, M., Abutaleb, A., Shin, H., Reneker, D., Chase, G. (2016). Fabrication, polarization of electrospun polyvinylidene fluoride electret fibers and effect on capturing nanoscale solid aerosols. Materials 9, 671. https://doi.org/10.3390/ma9080671

Łowkis, B., Motyl, E. (2001). Electret properties of polypropylene fabrics. J. Electrost. 51, 232238. https://doi.org/10.1016/S0304-3886(01)00053-5

Martin, S.B., Moyer, E.S. (2000). Electrostatic respirator filter media: Filter efficiency and most penetrating particle size effects. Appl. Occup. Environ. Hyg. 15, 609-617. https://doi.org/10.1 080/10473220050075617

Miguel, A. (2003). Effect of air humidity on the evolution of permeability and performance of a fibrous filter during loading with hygroscopic and non-hygroscopic particles. J. Aerosol. Sci. 34, 783-799. https://doi.org/10.1016/S0021-8502(03)00027-2

Ministry of Food and Drug Safety (MFDS) (2017). Guideline on Standards and Specifications for Filtering Respirators. Ministry of Food and Drug Safety (MFDS) in Korea.

Mostofi, R., Bahloul, A., Lara, J., Wang, B., Cloutier, Y., Haghighat, F. (2011). Investigation of potential affecting factors on performance of N95 respirators. J. Int. Soc. Respir. Prot. 28, 2639.

Motyl, E., Łowkis, B. (2006). Effect of air humidity on charge decay and lifetime of PP electret nonwovens. Fibres Text. East. Eur. 14, 59.

National Institute for Occupational Safety \& Health (NIOSH) (2019). Procedure no. TEB-APR-STP0051, 0052, 0053, 0054, 0055, 0056, 0057, 0058, 0059, Revision 3.2 (2019), Pittsburgh, PA: DHHS, Centers for Disease Control and Prevention, National Institute for Occupational Safety and Health, National Personal Protective Technology Laboratory. [serial online] 2005a. https://www.cdc.gov/niosh/npptl/stps/apresp.html (accessed 23 November 2021).

Newnum, J.D. (2010). The effects of relative humidity on respirator performance (Master of Science). University of lowa. https://doi.org/10.17077/etd.rfpsd6w8

Ramirez, J.A. (2015). Evaluation of particle penetration and breathing resistance of N95 filtering face-piece respirators and uncertified dust masks (Doctor of Philosophy). University of lowa. https://doi.org/10.17077/etd.wfvehzie

Rengasamy, A., Zhuang, Z., Berryann, R. (2004). Respiratory protection against bioaerosols: Literature review and research needs. Am. J. Infect. Control. 32, 345-354. https://doi.org/10.1 016/j.ajic.2004.04.199

Rengasamy, S., Eimer, B.C., Shaffer, R.E. (2009). Comparison of nanoparticle filtration performance of NIOSH-approved and CE-marked particulate filtering facepiece respirators. Ann. Occup. Hyg. 53, 117-128. https://doi.org/10.1093/annhyg/men086

Rengasamy, S., BerryAnn, R., Szalajda, J. (2013). Nanoparticle filtration performance of filtering facepiece respirators and canister/cartridge filters. J. Occup. Environ. Hyg. 10, 519-525. https://doi.org/10.1080/15459624.2013.818229

Roberge, R.J., Bayer, E., Powell, J.B., Coca, A., Roberge, M.R., Benson, S.M. (2010). Effect of exhaled moisture on breathing resistance of N95 filtering facepiece respirators. Ann. Occup. Hyg. 54, 671-677. https://doi.org/10.1093/annhyg/meq042

Shaffer, R.E., Rengasamy, S. (2009). Respiratory protection against airborne nanoparticles: A review. J. Nanopart. Res. 11, 1661. https://doi.org/10.1007/s11051-009-9649-3

Wang, S., Zhao, X., Yin, X., Yu, J., Ding, B. (2016). Electret polyvinylidene fluoride nanofibers hybridized by polytetrafluoroethylene nanoparticles for high-efficiency air filtration. ACS Appl. 
Mater. Interfaces. 8, 23985-23994. https://doi.org/10.1021/acsami.6b08262

Wang, S.C., Flagan, R.C. (1990). Scanning electrical mobility spectrometer. Aerosol Sci. Technol. 13, 230-240. https://doi.org/10.1080/02786829008959441

Yang, H.J., Kim, S.H., Jang, A.S., Kim, S.H., Song, W.J., Kim, T.B., Ye, Y.M., Yoo, Y., Yu, J., Yoon, J.S. (2015). Guideline for the prevention and management of particulate matter/yellow dustinduced adverse health effects on the patients with bronchial asthma. J. Korean Med. Assoc. 58, 1034-1043. https://doi.org/10.5124/jkma.2015.58.11.1034

Yang, S., Lee, G.W. (2005). Filtration characteristics of a fibrous filter pretreated with anionic surfactants for monodisperse solid aerosols. J. Aerosol. Sci. 36, 419-437. https://doi.org/10.1 016/j.jaerosci.2004.10.002 